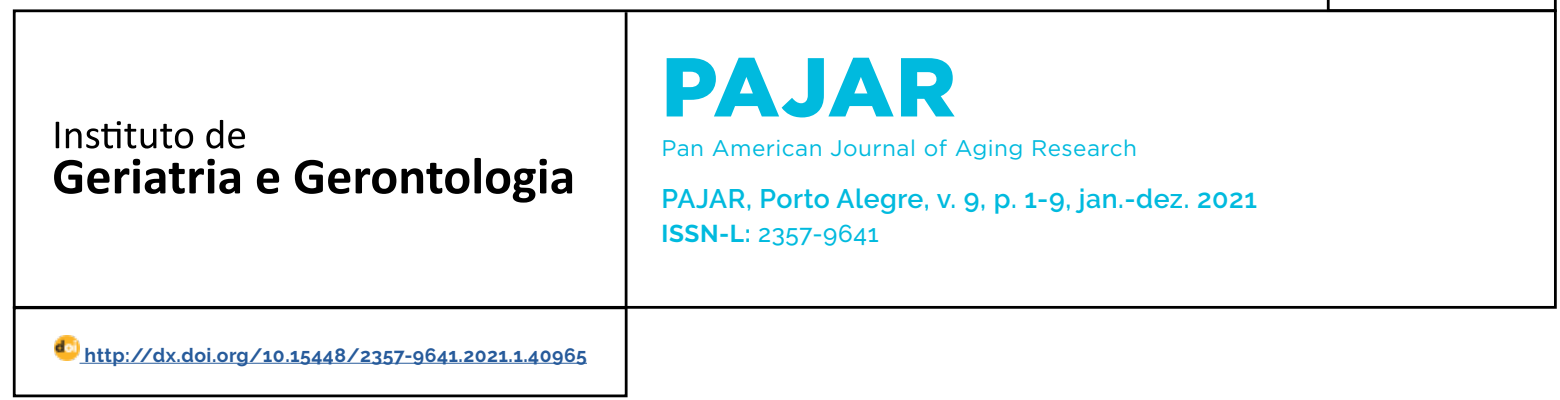

\title{
Associação entre níveis de ocitocina e estilos de apego numa amostra de idosos da Estratégia Saúde da Familia
}

\author{
Association between ocytocin levels and attachment styles in an sample elderly of \\ Family Health Strategy \\ Asociación entre niveles de oxitocina y estilos de adhesión en una muestra de ancianos \\ de Estrategia Ssalud de la Familia
}

\section{Guilherme Marcos}

\section{Nogueira $^{1}$}

orcid.org/0000-0002-0527-6175 quilhermeneurociencia@gmail.com

\section{Paula Engroff ${ }^{1}$}

orcid.org/0000-0002-3639-545X

paula.engroff@pucrs.br

\section{Maria Gabriela Valle}

Gotllieb²

orcid.org/0000-0002-7694-0336

vallegot@hotmail.com

\section{Armin von Gunten}

orcid.org/0000-0001-7852-3803

armin.von-gunten@chuv.ch

Gabriel Behr Gomes

Jardim $^{3}$

orcid.org/0000-0001-7937-8185

gabriel.behr@chuv.ch

\section{Alfredo Cataldo Neto ${ }^{1}$}

orcid.org/0000-0002-8082-1866 cataldo@pucrs.br

Recebido em: 21 maio 2021. Aprovado em: 29 jun. 2021 Publicado em: 26 ago. 2021.

\section{Resumo}

Objetivo: o objetivo desse estudo é identificar o perfil de apego de uma amostra de idosos da Estratégia Saúde da Família e verificar a associação com níveis de ocitocina no soro.

Método: foi realizado um estudo transversal, descritivo e analítico com pacientes idosos, atendidos na Estratégia de Saúde da Familia em Porto Alegre, RS. Foram investigadas as variáveis sociodemográficas, ocitocina e estilos de apego. Os instrumentos utilizados foram o Questionário Geral do Programa de Envelhecimento Cerebral (PENCE) para dados sociodemográficos e o Relationship Scale Questionnaire (RSQ) para estilos de apego. A ocitocina foi obtida através do soro e mensurada por meio da técnica de Enzyme-Linked Immunosorbent Assay (ELISA) Resultados: foram investigados 108 idosos, com prevalência do sexo feminino $(73,1 \%)$ e média de idade de 71,8 anos. Foi observado uma correlação positiva entre ocitocina e apego seguro $(p<0,05)$ e $(r=0,195)$. Os resultados demonstraram, também, diferença estatisticamente significativa nos estilos de apego ansioso e medroso, entre os sexos.

Conclusão: os achados deste estudo reforçam o importante papel da ocitocina como molécula moduladora do funcionamento social, reforçando a ideia de que, esse neuropeptideo se apresenta como potencial elo entre a neurofisiologia e a formação do vínculo de apego seguro. Nossos dados sugerem, também, que o gênero pode se apresentar como aspecto influenciador na formação do apego, ampliando ainda mais a discussão acerca da neutralidade, proposta pelo modelo clássico da teoria do apego. Palavras-chave: idoso, ocitocina, vínculo afetivo.

\section{Abstract}

Objective: the objective of this study is to identify the attachment profile of an elderly sample from the Family Health Strategy and to verify the association with serum oxytocin levels.

Method: a cross-sectional, descriptive and analytical study was carried out with elderly patients assisted by the Family Health Strategy in Porto Alegre/RS. Sociodemographic variables, oxytocin and attachment styles were investigated. The instruments used were the General Brain Aging Program Questionnaire PENCE for sociodemographic data; Relationship Scale Questionnaire - RSQ for attachment styles. Oxytocin was obtained through serum and measured using the Enzyme-Linked Immunosorbent Assay - ELISA technique.

Results: 108 elderly people were investigated, with a female prevalence (73.1\%) and a mean age of 71.8 years. A positive correlation was observed between oxytocin and secure attachment $(p<0.05)$ and $(r=0.195)$. The results also showed a statistically significant difference in anxious and fearful attachment styles, between genders.

Conclusion: the findings of this study reinforce the important role of oxytocin as a 
molecule that modulates social functioning, reinforcing the idea that this neuropeptide presents itself as a potential link between neurophysiology and the formation of a secure attachment bond. Our data also suggest that gender can present itself as an influencing aspect in the formation of attachment, further expanding the discussion about neutrality, proposed by the classic model of attachment theory.

Keywords: aged, oxytocin, affective bond.

\section{Resumen}

Objetivo: el objetivo de este estudio es identificar el perfil de apego de una muestra de ancianos de la Estrategia Salud de la Familia y verificar la asociación con los niveles séricos de oxitocina.

Método: se realizó un estudio transversal, descriptivo y analítico con pacientes ancianos asistidos por la Estrategia Salud de la Familia en Porto Alegre / RS. Se investigaron variables sociodemográficas, oxitocina y estilos de apego. Los instrumentos utilizados fueron el Cuestionario del Programa General de Envejecimiento Cerebral - PENCE para datos sociodemográficos; Cuestionario de escala de relación: RSQ para estilos de apego. La oxitocina se obtuvo a través del suero y se midió mediante el ensayo inmunoabsorbente ligado a enzimas - técnica ELISA

Resultados: se investigaron 108 ancianos, con una prevalencia femenina $(73,1 \%$ ) y una edad media de 71,8 años. Se observó una correlación positiva entre la oxitocina y el apego seguro $(p<0,05)$ y $(r=0,195)$. Los resultados también mostraron una diferencia estadisticamente significativa en los estilos de apego ansioso y temeroso, entre géneros.

Conclusión: los hallazgos de este estudio refuerzan el importante papel de la oxitocina como molécula que modula el funcionamiento social, reforzando la idea de que este neuropéptido se presenta como un vínculo potencial entre la neurofisiología y la formación de un vínculo de apego seguro. Nuestros datos también sugieren que el género puede presentarse como un aspecto influyente en la formación del apego, ampliando aún más la discusión sobre la neutralidad, propuesta por el modelo clásico de la teoría del apego. Palabras clave: anciano, oxitocina, vinculo afectivo.

\section{Introdução}

A ocitocina desempenha importantes funções periféricas e centrais, o que a coloca como foco de pesquisa ao longo das últimas décadas. ${ }^{1}$ Ações periféricas de efeito uterotônico e constrição dos ductos mamários, são bem descritos na literatura e, assim, bem esclarecidos. ${ }^{2}$ Por outro lado, a literatura tem evidenciado a potencial influência desse neuropeptídeo em diferentes funções centrais relacionadas ao comportamento social, ${ }^{3.4}$ formação de laços afetivos, ${ }^{5.6}$ confiança, ${ }^{7}$ empatia, ${ }^{8}$ socialização, ${ }^{9}$ comportamento parenta ${ }^{10} \mathrm{e}$ modulação no processamento de pistas sociais. ${ }^{11}$ Esse neuropeptideo, produzido pelas regiões supraótica e paraventricular do hipotálamo, é liberado pela hipófise posterior e desempenha suas funções se ligando a receptores especificos (OXTR), distribuidos amplamente no cérebro. ${ }^{12}$

Áreas limbicas e corticais que, em conjunto, desempenham importantes funções na formação dos diferentes estilos de apego, motivação, comportamento direcionado a objetivos, envolvimento social, memória social, processamento cognitivo e emocional, dispõem de uma grande densidade de receptores ocitocinérgicos $(\mathrm{OXTR})^{13.14} \mathrm{e}$ colocam a ocitocina, uma molécula muito antiga do ponto de vista evolutivo, como agente basilar desses processos.

O vínculo de apego em humanos tem um papel crucial no desenvolvimento, envolve áreas especificas relacionadas ao funcionamento social e parece ser fortemente modulado pela ação do sistema ocitocinérgico. ${ }^{15}$ Grande parte dessa influência da ocitocina na formação do apego deriva da interação e afinidade com outros sistemas neuroquímicos, como o sistema dopaminérgico nas áreas de reconhecimento do valor hedôni$\mathrm{CO}^{16,17}$ e atenuação da percepção de ameaça.. ${ }^{18}$ Alterações marcantes nos níveis de ocitocina são evidenciados em indivíduos com distúrbio na formação de apego, demonstrando sérios prejuizos no processamento afetivo/emocional e organização do comportamento social. ${ }^{19.20}$

A qualidade dos laços afetivos reflete modelos de representação mental e conduta social, influenciando em diferentes aspectos do envelhecimento. ${ }^{21}$ No idoso, uma base segura de apego tem se mostrado associada a aspectos como confiança, autoaceitação, resiliência emocional, autocompaixão, maior aceitação de ajuda e maior busca de apoio social..22 Por outro lado, estilos de apego inseguro, como ansioso e evitativo, aumentam os riscos para desfechos ruins no envelhecimento como comportamentos autolesivos, suicidio, desprezo pelo apoio social, isolamento, além de prejuizos para a saúde mental. ${ }^{23.24}$

As questões acima dispostas, direcionam para reflexões acerca da influência desse neuropeptídeo na formação dos laços afetivos e na configuração dos diferentes estilos de apego. É sob esta esteira, que o presente artigo tem como objetivo apresentar o perfil de apego em uma 
amostra de idosos atendidos pela Estratégia de Saúde da Familia (ESF) e verificar a associação com niveis de ocitocina no soro.

\section{Método}

\section{Delineamento}

Estudo transversal, descritivo e analítico com pacientes idosos, atendidos na Estratégia de Saúde da Familia (ESF), em Porto Alegre, RS.

\section{População e amostra}

A amostra foi composta por 108 idosos participantes de um subprojeto intitulado "Impacto de fatores pré-mórbidos na expressão clínica de idosos brasileiros com quadro inicial de declínio cognitivo: uma coorte de indivíduos com baixa escolaridade", que fez parte de um estudo de maior abrangência denominado Programa de Envelhecimento Cerebral (PENCE), desenvolvido por pesquisadores da Pontificia Universidade Católica do Rio Grande do Sul (PUCRS), em parceria com a Secretaria Municipal de Saúde (SMS), de Porto Alegre, RS. Teve como objetivo implementar um modelo de atenção à saúde mental para indivíduos a partir dos 55 anos, por meio do rastreamento, avaliação e acompanhamento dos pacientes atendidos pela ESF. Os participantes foram avaliados, primeiramente, nas Unidades Básicas de Saúde (UBS) e, posteriormente, no ambulatório de Psiquiatria e Geriatria do Hospital São Lucas da PUCRS, por geriatras e psiquiatras treinados. A dosagem de ocitocina derivou da coleta de sangue realizada no Laboratório de Bioquímica e Genética Molecular (LABGEM), do Instituto de Geriatria e Gerontologia da PUCRS, acondicionado em tubo contendo ativador de coagulação, centrifugado por 10 minutos em 4000 rpm e armazenado em temperatura de $-80^{\circ} \mathrm{C}$, para posterior análise.

Foram excluídos do estudo os idosos com diagnóstico de demência, doenças graves, alterações na comunicação e na capacidade cognitiva, que inviabilizassem a adequada aplicação dos instrumentos de coleta, além dos idosos com outros transtornos psiquiátricos graves como esquizofrenia.

O tamanho amostral foi calculado a partir de um estudo piloto, com 27 individuos e obtido por meio do programa WinPEPI (Programs for Epidemiologists for Windows) versão 11.43. Para o estudo foi considerado um nível $\alpha$ de $5 \%(p<0,05)$, poder de $85 \%$ e um tamanho de efeito padronizado de no mínimo 0,6 DP.

\section{Variáveis investigadas}

Foram avaliadas variáveis sociodemográficas relacionadas ao sexo, idade e escolaridade. Os estilos de apego foram avaliados por meio do Relationship Scales Questionnaire (RSQ), instrumento composto por 30 itens, baseado em três escalas de apego anteriormente propostas, que permitiu identificar diferentes estilos de apego como seguro, ansioso, evitativo, preocupado, medroso e dispensado. O protocolo foi traduzido e validado para o português, de acordo com uma escala Likert, com variação de pontuação de 1 a 5. A classificação do apego foi calculada através da soma da pontuação de cada item específico, correspondente ao estilo de apego e calculada a média. Quanto maior a média, maior o estilo de apego apresentado. ${ }^{25}$ Os niveis de ocitocina foram dosados por meio de soro e quantificados utilizando o método Enzyme-Linked Immunosorbent Assay (ELISA), utilizando kits comerciais, IBL-international-TECANHamburg-Germany, seguindo o protocolo do fabricante. Os valores considerados de referência, dentro do limite normal da ocitocina, estão entre 1,5 e 250 pg/ml.

\section{Aspectos éticos}

Esse estudo foi devidamente aprovado pelo Comitê de Ética em Pesquisa da Pontifícia Universidade Católica do Rio Grande do Sul - CEP/ PUCRS sob o n. ${ }^{\circ}$ de parecer 826.858, pelo Comitê de Ética em Pesquisa da Secretaria Municipal de Saúde de Porto Alegre (parecer consubstanciado n. ${ }^{\circ}$ 1.003.962) e pelo Conselho Nacional de Ética em Pesquisa - CONEP sob o n. ${ }^{\circ}$ de parecer 948.938, cumprindo com todos os preceitos éticos descritos na Resolução 196/96 do Conselho Nacional e do Ministério da Saúde CNS/ MS, atualizada pela Resolução 466/2012. Todos os participantes deste estudo assinaram o Termo de Consentimento Livre e Esclarecido (TCLE). 


\section{Análise estatistica}

A comparação de médias entre os grupos foi realizada utilizando os testes t-Student ou Análise de Variância (ANOVA). Nos casos em que houve assimetria, os testes de Mann-Whitney e Kruskal-Wallis foram utilizados, respectivamente. O teste de correlação linear de Spearman foi utilizado nas associações entre variáveis numéricas e ordinais. O nivel de significância adotado foi de $5 \%(p<0,05)$ e as análises foram realizadas no programa Software Statistical Package for the Social Sciences (SPSS), versão 21.0.

\section{Resultados}

A amostra foi composta por 108 idosos, com variação etária entre 60 e 87 anos. A média de idade foi de $71,8 \pm 6,5$ anos, com predominância do sexo feminino (73,1\%). A escolaridade, categorizada nos niveis de não alfabetizados, alfabetizados até a $4 .{ }^{\text {a }}$ série, ensino fundamental incompleto/ completo, ensino médio incompleto/completo e ensino superior incompleto/completo, demonstrou predominância de escolaridade em nivel de alfabetizados até a $4^{a}$ série (37\%), o que evidencia nessa amostra, um perfil de baixa escolaridade. Os niveis de ocitocina foram descritos por quartis (Q1: $\leq$ 7,4; Q2: 7,41 - 19,2; Q3: 19,3 - 51,2 e Q4: >51,2), dada a heterogeneidade da amostra. A média da ocitocina foi de $41,4 \mathrm{pg} / \mathrm{ml}$ com desvio padrão de 54,8 pg/ $\mathrm{ml}$. Por ser uma variável assimétrica e com elevado desvio padrão, optou-se por utilizar a mediana, que foi de 19,2 e amplitude interquartílica (Tabela 1).

No que se refere ao perfil de apego, nossos resultados demonstram que o estilo de apego evadido/evitativo se apresenta com maior média $(22,8 \pm 5,0)$ e o estilo preocupado, com menor média $(11,4 \pm 3,0)$, na amostra investigada. Quando comparadas as médias entre homens e mulheres, os resultados apontam para diferenças estatisticamente significativas no estilo de apego medroso, mostrando que as mulheres apresentam escores mais elevados que os homens $(p<0,05)$. Outro resultado estatisticamente significativo, na comparação entre homens e mulheres da amostra, revela que as mulheres apresentam escores mais elevados de estilo de apego ansioso $(p<0,01)$ (Tabela 2).
$\mathrm{Na}$ avaliação acerca dos níveis de ocitocina no soro e estilos de apego na amostra total, os resultados demonstram correlação positiva de Spearman, entre ocitocina e apego seguro, ou seja, quanto maior os niveis de ocitocina, maior o escore nesse estilo de apego $(p<0,05)\left(r_{s}=0,195\right)$. Mesmo quando ajustado para sexo e idade, pelo modelo de Regressão Linear Multivariado, a associação permanece significativa ( $b=0,014$; IC 95\%: 0,002 a 0,026; $\mathrm{p}=0,028$ ), com os niveis de ocitocina explicando $5,4 \%$ da variabilidade do estilo de apego seguro ou vice-versa. Não houve diferença, estatisticamente significativa, entre niveis de ocitocina e os demais estilos de apego, na comparação entre gêneros e na amostra total. Quanto aos niveis de ocitocina, a mediana não apresentou diferença, estatisticamente significativa, entre homens e mulheres (26,3 vs 19,0; $p=0,155$ ) (dados não demonstrados) (Tabela 3).

Tabela 1 - Distribuição das frequências do perfil sociodemográfico, média e classificação dos niveis séricos de ocitocina dos idosos, $\mathrm{n}=108$

\begin{tabular}{|c|c|}
\hline Variáveis & n (\%) \\
\hline \multicolumn{2}{|l|}{ Sexo } \\
\hline Masculino & $29(26,9)$ \\
\hline Feminino & $79(73,1)$ \\
\hline Idade (anos)* & $71,8 \pm 6,5$ \\
\hline \multicolumn{2}{|l|}{ Nivel de escolaridade } \\
\hline Analfabeto & $9(8,3)$ \\
\hline Alfabetizado até $4^{a}$ série & $40(37,0)$ \\
\hline $\begin{array}{l}\text { Ensino fundamental incompleto/ } \\
\text { completo }\end{array}$ & $33(30,6)$ \\
\hline Ensino médio incompleto/completo & $23(21,3)$ \\
\hline Ensino superior incompleto/completo & $3(2,8)$ \\
\hline Ocitocina $(\mathrm{pg} / \mathrm{ml})^{* *}$ & $19,2(7,4$ a 51,2$)$ \\
\hline \multicolumn{2}{|l|}{ Classificação da Ocitocina } \\
\hline Q1 & $28(25,9)$ \\
\hline Q2 & $27(25,0)$ \\
\hline Q3 & $26(24,1)$ \\
\hline Q4 & $27(25,0)$ \\
\hline
\end{tabular}

* descrita por média \pm desvio padrão; * descrita por mediana (percentis 25-75);

Q1: Quartil 1 ( $\leq 7,4 \mathrm{pg} / \mathrm{ml}$ ), Q2: Quartil 2 (entre 7,41 e 19,2 pg/ml), Q3=Quartil 3 (entre 19,3 e 51,2 pg/ml) e Q4= Quartil 4 (acima de 51,2 pg/ml). 
Tabela 2 - Associação entre gênero e os estilos de apego nos idosos da amostra

\begin{tabular}{|c|c|c|c|c|}
\hline \multirow{2}{*}{ Estilos de apego } & $\begin{array}{l}\text { Amostra total } \\
\quad(n=108)\end{array}$ & $\begin{array}{l}\text { Homens } \\
(n=29)\end{array}$ & $\begin{array}{l}\text { Mulheres } \\
\quad(n=79)\end{array}$ & \multirow{2}{*}{$\mathbf{p}^{*}$} \\
\hline & Média \pm DP & Média \pm DP & Média \pm DP & \\
\hline Seguro & $15,6 \pm 3,5$ & $16,4 \pm 3,7$ & $15,4 \pm 3,5$ & 0,167 \\
\hline Medroso & $13,0 \pm 3,4$ & $11,8 \pm 3,5$ & $13,4 \pm 3,3$ & 0,032 \\
\hline Preocupado & $11,4 \pm 3,0$ & $11,4 \pm 2,9$ & $11,4 \pm 3,1$ & 0,960 \\
\hline Dispensado & $18,8 \pm 3,1$ & $19,3 \pm 2,7$ & $18,7 \pm 3,2$ & 0,406 \\
\hline Evadido/Evitativo & $22,8 \pm 5,0$ & $22,4 \pm 4,2$ & $23,0 \pm 5,2$ & 0,605 \\
\hline Ansiedade & $11,7 \pm 4,8$ & $9,6 \pm 4,2$ & $12,4 \pm 4,8$ & 0,008 \\
\hline
\end{tabular}

DP=Desvio Padrão; * valores obtidos através do teste t-Student para amostras independentes.

Tabela 3 - Associação entre estilos de apego e niveis de ocitocina na amostra geral e na comparação entre gêneros

\begin{tabular}{lcccccc}
\hline \multirow{2}{*}{ Estilos de apego } & \multicolumn{5}{c}{ Ocitocina (pg/ml) } \\
\cline { 2 - 6 } & \multicolumn{2}{c}{ Amostra total } & Homens & Mulheres \\
\cline { 2 - 6 } & $\mathbf{r}_{\mathrm{s}}$ & $\mathbf{p}$ & $\mathbf{r}_{\mathrm{s}}$ & $\mathbf{p}$ & $\mathbf{r}_{\mathrm{s}}$ & $\mathbf{p}$ \\
\hline Seguro & 0,195 & $\mathbf{0 , 0 4 5}$ & 0,159 & 0,419 & 0,201 & 0,078 \\
Medroso & $-0,012$ & 0,904 & 0,223 & 0,253 & $-0,040$ & 0,729 \\
Preocupado & 0,060 & 0,543 & 0,138 & 0,485 & 0,040 & 0,728 \\
Dispensado & $-0,065$ & 0,509 & 0,066 & 0,740 & $-0,116$ & 0,310 \\
Preocupado-outro & 0,071 & 0,470 & 0,037 & 0,853 & 0,075 & 0,516 \\
Ansiedade & $-0,007$ & 0,946 & 0,196 & 0,318 & $-0,017$ & 0,882 \\
\hline
\end{tabular}

$r_{\mathrm{s}}$ coeficiente de correlação de Spearman.

\section{Discussão}

Este estudo investigou os estilos de apego e a associação com níveis de ocitocina no soro em uma amostra de idosos. As principais descobertas ficaram por conta da associação entre niveis de ocitocina e estilo de apego seguro, na amostra geral, e a diferença entre os estilos de apego medroso e ansioso, na comparação entre gêneros, mostrando que as mulheres apresentam escores mais elevados do que os homens.

O envelhecimento é um processo inexorável, que atinge todos os componentes orgânicos, e o impacto global no indivíduo é resultante de alterações hierarquicamente organizadas, que operam em nivel molecular, celular, fisiológico e funcional. Esse processo segue um curso que depende da composição genética, mas que também sofre importante influência do ambiente e do estilo de vida. Fatores como satisfação com a vida, prolongamento do tempo médio de vida, preservação das capacidades funcionais e engajamento com a vida, são características de um envelhecimento "bem-sucedido"., 6

Os padrões de vínculo de apego podem influenciar desejos de engajamento, relacionamentos sociais e busca de apoio social, além de se mostrarem 
associados a alterações na saúde física e mental em idosos. ${ }^{21}$ Instabilidade afetiva, decorrentes de prejuízos na formação de apego, demonstram apresentar maior risco para a saúde mental, intimidade nos relacionamentos, confiança e comportamentos autolesivos em fases avançadas da vida.

As diferenças entre os sexos encontradas na nossa amostra, em relação aos estilos de apego, não se ajustam à teoria clássica do apego, a qual é estabelecida sobre bases sexualmente neutras e não prevê, nem explica, diferenças de estilos entre homens e mulheres. Porém, considerando que o apego adulto não se estabelece somente pela necessidade de amparo às necessidades de sobrevivência, mas adiciona perspectivas de custo e benefício em relação a outros aspectos psíquicos, esses modelos mentais de necessidade e desejo no adulto podem sofrer influência de fatores ecológicos e sociais. ${ }^{27} \mathrm{O}$ apego romântico no adulto se mostra como exemplo da diferença entre os sexos e mesmo que apresente tamanho de efeito da média mundial pequeno, desafia fortemente o modelo clássico de neutralidade, sustentando nossos achados. ${ }^{28}$

Nossos resultados acerca da diferença de estilos de apego entre os sexos, encontram apoio também em estudo realizado com homens e mulheres jovens e idosos, que testou a desregulação emocional como mediador da associação entre apego inseguro e agressão psicológica, demonstrando niveis mais elevados de apego ansioso em mulheres. ${ }^{29}$ As diferenças nos estilos de apego entre homens e mulheres podem ser observadas, ainda, em estudo sobre o efeito mediador da atenção plena na relação entre apego e medo da perda do contato social virtual, os resultados mostram que há diferença significativa nos estilos de apego, com base no sexo, com pontuações mais altas de apego ansioso nas mulheres..$^{30}$

Ainda assim, a questão que envolve a diferença entre os sexos nos estilos de apego se mantém em ampla discussão e, mesmo que nossos achados tenham demonstrado diferenças estatisticamente significativas entre os estilos de apego, comparando homens e mulheres adultos, alguns estudos ${ }^{31.32}$ apresentam resul- tados conflitantes. Essas diferenças de estilos de apego entre os gêneros também não foram evidenciadas quando se buscou examinar o papel moderador do processamento emocional na relação entre os estilos de apego e a gravidade dos sintomas somáticos experimentados pelos indivíduos, mesmo demonstrando que a gravidade dos sintomas somáticos tenha sido significativamente maior nas mulheres. ${ }^{32}$ Esses resultados, além de não se colocarem em consonância com nossos achados, direcionam para uma peculiaridade da nossa amostra e ampliam a perspectiva de que a formação dos estilos de apego não, necessariamente, segue um padrão independentemente do sexo.

No que se refere aos efeitos da idade nos niveis de ocitocina, a literatura ainda se mantém limitada. Nossos resultados demonstraram que a ocitocina está significativamente associada com a formação de estilo de apego seguro, corroborando com um extenso e robusto campo de investigação que coloca esse neuropeptídeo como base neurofisiológica da formação de vínculos de apego e de comportamento social. ${ }^{33.34}$

Estudos recentes, ${ }^{35-37}$ sugerem associação entre desregulação do sistema ocitocinérgico, com niveis plasmáticos de ocitocina reduzidos, e transtornos do comportamento social, distúrbios dos vínculos de apego e das relações sociais. ${ }^{35} \mathrm{Na}$ relação da diade mãe-bebê já é possivel identificar essa relação da ocitocina com vinculo de apego, onde niveis mais elevados desse neuropeptídeo se mostram associados a maior cuidado materno e apego afetuoso mais seguro. ${ }^{6}$ No que se refere ao apego em adultos, a ocitocina modula uma ligação mais positiva e mecanismos proximais no apego romântico. ${ }^{37}$

Outro mecanismo desencadeado pela ação do sistema ocitocinérgico e que direciona para a formação de vínculo de apego seguro, é a atenuação do processamento do medo e a melhora da sensação de recompensa. ${ }^{38}$ Nosso estudo se coloca em consonância com essa gama de resultados, acima descritos, evidenciando associação positiva entre niveis de ocitocina e estilos de apego seguro, independentemente do sexo. Porém, não foi encontrada correlação, estatis- 
ticamente significativa, entre concentração de ocitocina e demais estilos de apego, sugerindo outros fatores como influentes.

Sobre a ocitocina, um fator de confusão poderia ser pensado em virtude da provável relação entre ocitocina periférica e ocitocina central, a qual ainda não se apresenta totalmente esclarecida. O crescente corpo de evidências acerca dessa questão demonstra, por um lado, que em ambos os niveis as concentrações de ocitocina parecem coordenadas, ${ }^{39}$ mas, por outro lado, existem investigações que divergem dessa perspectiva.

\section{Conclusão}

Com base nos nossos achados, foi possivel demonstrar a participação da ocitocina na formação de vínculo de apego seguro, ampliando as bases da literatura científica acerca da função desse neuropeptídeo no funcionamento social do idoso. Nosso estudo permitiu, também, compreender as diferenças entre sexo e estilos de apego, sugerindo que o gênero pode se apresentar como aspecto influenciador da formação de vínculo, o que se contrapõe ao modelo clássico da teoria do apego e amplia a discussão acerca da neutralidade.

\section{Limitações}

Dentro das limitações que esse estudo apresenta, e talvez o mais expressivo, está o modelo do estudo. Utilizamos um desenho transversal o qual limita a análise a indicadores extraídos em um único momento, possibilitando análise de correlações, mas limitando a compreensão causal. Outro fator limitante diz respeito à falta de conhecimento acerca do histórico vivencial e estilo de vida, aspectos que podem influenciar na atividade da ocitocina e ocultar fatores mediadores. Além disso, há de se considerar que, para este estudo, foram utilizadas amostras de ocitocina no soro, o que pode não representar de maneira fidedigna os impactos centrais.

\section{Conflitos de interesse}

Os autores assumem que o conteúdo desse estudo não apresenta conflito de interesse.

\section{Agradecimentos}

Os autores agradecem aos profissionais da Estratégia de Saúde da Familia do municipio de Porto Alegre, RS.

\section{Fonte de financiamento}

Este estudo foi apoiado por bolsa da Coordenação de Aperfeiçoamento de Pessoal de Nivel Superior (CAPES) e edital do Projeto Visitante Especial (PVE) A031.

\section{Referências}

1. Jurek B, Neumann ID. The Oxytocin Receptor: From Intracellular Signaling to Behavior. Physiol Rev. 2018;1;98(3):1805-1908.

2. Arrowsmith S, Wray S. Oxytocin: its mechanism of action and receptor signalling in the myomeytium. J. Neuroend. 2014:26(6):356-69.

3. Steinbach X, Maasen S. Oxytocin: From a Hormone for Birth to a Social Hormone: The Hormonal Governance of Sociability aka Society. NMT. 2018;26(1):1-30.

4. Ebert A, Brüne M. Oxytocin and social cognition. Curr Top Behav Neurosci. 2018:35:375-88.

5. Love MT. Oxytocin, motivation and the role of dopamine. Pharmacol Biochem.Behav. 2014;119:49-60.

6. Kendrick KM, Guastella AJ, Becker B. Overview of humam oxytocin research. Curr. Top. Behav. Neurosci. 2018:35:321-48.

7. Zhong S, Monakhov M, Mok HP, Tong T, San Lai P, Chew SH, et al. U-shaped relation between plasma oxytocin levels and behavior in the trust game. PLoS One. 2012;7: e51095.

8. Palgi S, Klein E, Shamay-Tsoory S. The role of oxytocin in empathy in PTSD. Psychol Trauma. 2017:9(1):70-5.

9. Weisman O, Zagoory-Sharon O, Feldman R. Oxytocin administration to parent enhances infant physiological and behavioral readiness for social engagement. Biol Psychiatry. 2012;72: 982-9.

10. Feldman R. Oxytocin and social affiliation in humans. Horm Behav. 2012;61(3):380-91.

11. Kanat M, Heinrichs M, Schwarzwald R, Domes G. Oxytocin attenuates neural reactivity to masked threat cues from the eyes. Neuropsychopharmacology. 2015;40: 287-95.

12. Poisbeau P, Grinevich V, Charlet A. Oxytocin signaling in pain: cellular, circuit, system, and behavioral levels. Curr Top Behav Neurosci. 2018;35:193-211.

13. Zhang X, Deng M, Ran G, Tang Q, Xu W, Ma Y, et al. Brain correlates of adult attachment style: a voxel-based morphometry study. Brain Research. 2018;1699:34-43. 
14. Boccia ML, Petrusz P, Suzuki K, Marson L, Pedersen CA. Immunohistochemical Localization of Oxytocin Receptors in Human Brain. Neuroscience. 2013:3(253):155-64.

15. Johnson ZV, Young LJ. Neurobiological mechanisms of social attachment and pair bonding. Curr Opin Behav Sci. 2015:3:38-44.

16. Gregory R, Cheng H, Rupp HA, Sengelaub DR, Heiman JR. Oxytocin increases VTA activation to infant and sexual stimuli in nulliparous and postpartum women. Horm Behav. 2015;69:82-8.

17. Hu J, Qi S, Becker B, Luo L, Gao S, Gong Q, et al. Oxytocin selectively facilitates learning with social feedback and increases activity and functional connectivity in emotional memory and reward processing regions. Hum. Brain Mapp. 2015:36:2132-46.

18. Matsushita H. Oxytocin and Stress: Neural mechanisms, stress-related disorders, and therapeutic approaches. Neuroscience. 2019;417:1-10.

19. Toepfer P, Heim C, Entringer S, Binder E, Wadhwa $P$, Buss $C$. Oxytocin pathways in the intergenerational transmission of maternal early life stress. Neurosci. Biobehav. Rev. 2017:73:293-308

20. Smearman EL, Almli LM, Conneely KN, Brody GH, Sales JM, Bradley B, et al. Oxytocin receptor genetic and epigenetic variation: Association with child abuse and adult psychiatric symtoms. Child. Dev. 2016;87(1):122-34.

21. Walsh E, Blake Y, Donati A, Stoop R, Gunten A. Early Secure Attachment as a Protective Factor Against Later Cognitive Decline and Dementia. Front. Aging. Neurosci. 2019:(11):161.

22. Homan KJ. Secure Attachment and Eudaimonic Well-Being in Late Adulthood: The Mediating Role of Self-Compassion. Aging Ment Health. 2016;22(3):363-70.

23. Oon-Aron A. Suicidality in the elderly: role of adult attachment. Asian J. Psychiatr 2019;(44):8-12.

24. Laird KT, Krause B, Funes C, Lavretsky H. Psychobiological factors of resilience and depression in late life. Transl psychiatry. 2019;(9):88

25. Assis EM, Loureiro FS, Menta C, Nogueira EL, Filho IGS, von Gunten A, Neto AC. Translation and Brazilian adaptation of the Relationship Scales Questionnaire (RSQ). Trends Psychiatry Psychother. 2019;41(1):69-77.

26. Martin P, et al. Defining Successful Aging: A Tangible or Elusive Concept? Gerontologist. 2017:55(1):14-25.

27. Del Giudice M. Sex diferences in attachment styles. Curr. Opin. Psychol. 2019;25:1-5.

28. Del Giudice M. Sex differences in romantic attachment: a meta-analysis. Pers. Soc. Psychol. Bull. 2011:37(2):193-214

29. Hoover RC, Jackson JB. Insecure Attachment, Emotion Dysregulation and Psychological Aggression in Couples. J Interpers Violence. 2019;1-29.

30. Arpaci I, Baloglu M, Kozan HIO, Kesici S. Individual diferences in the Relationship Between and nomophobia Among College Students: The Mediating Role of Mindfulness. J Med Internet Res.2017;19(12):e404.
31. Perez-Aranha Gl, Peralta-Lópes V, Estrada-Carmona S, Reyes LG, Tuz-Sierra MA. Attachment and Adulthoodin a Sample of Southeastern Mexico. Behav Sci. (Basel). 2019;9(12):134

32. Falahatdoost M, Dolatsshahi B, Pourshahbaz A, Dehghani D, Yalguzaghaji MN, Mohammadi Z. Modeling the relatioship between attachment styles and somatic symptoms with the mediating role of emotional processing. J Educ Health Promot. 2020;30(9):157.

33. Feldman R. The neurobiology of human attachment. Trends in Cogn Sci 2017:(21):80-99.

34. MacDonald K, Mac Donald TM. The peptide that binds: a systematic review of ocytocin and its prosocial effects in humans. Harv. Rev. Psychiatry. 2010;18:1-21.

35. Kroll-Desrosiers AR, Sobrinho BC, Babb JA, Guilarte-Walker Y, Moore Simas TA, Deligiannidis KM. Association of peripartum synthetic oxytocin administration and depressive and anxiety disorders within the first postpartum year. Depress Anxiety. 2017:34(2):137-46.

36. Swain JE, Kim P, Spiccer J, Ho SS, Dayton CJ, Elmadih $A$, et al. Approaching the biology of human parental attachment: brain imaging, oxytocin and coordinated assessments of mothers and fathers. Brain Res. 2014:1580:78-101.

37. Sara BA, Laura EK, Karen G. Oxytocin and social bonds: the role of oxytocin in perceptions of romantic partners bonding behavior. Psychol Sci. 2017;28(12):1763-72.

38. Maroun M, Wagner S. Oxytocin and Memory of Emotional Stimulus Some Dance to Remember, Some Dance to Forget. Biol Psychiatry. 2016;79(3):203-12.

39. Carson DS, Berquist SW, Trujillo TH, Garner JP, Hannah SL, Hyde, SA, et al. Cerebrospinal fluid and plasma oxytocin concentrations are positively correlated and negatively predict anxiety in children. Mol Psychiatry. 2014:20:1085-90

\section{Guilherme Marcos Nogueira}

Doutor em Gerontologia Biomédica pela Pontificia Universidade Católica do Rio Grande do Sul (PUCRS), em Porto Alegre, RS, Brasil.

\section{Paula Engroff}

Farmacêutica. Doutora em Gerontologia Biomédica pela Pontificia Universidade Católica do Rio Grande do Sul (PUCRS), em Porto Alegre, RS, Brasil.

\section{Maria Gabriela Valle Gotllieb}

Biogerontologista. PhD em Ciências da Saúde pela Pontifícia Universidade Católica do Rio Grande do Sul (PUCRS), em Porto Alegre, RS, Brasil. Escritora e Terapeuta Integrativa em Saúde. Consultora da UNESCO para o Projeto RS Amigo do Idoso. 


\section{Armin von Gunten}

Medical Doctor. Postdoctoral fellowships at the National Hospital for Neurology and Neurosurgery in London, United Kington and at the Fishberg Research Center for Neurobiology, Mount Sinai School of Medicine in New York, USA. Professor of old-age psychiatry at the Lausanne University Hospital and the head of the old-age psychiatry service of the CHUV in Lausanne, Switzerland. Director of the Collaborating Centre for old-age psychiatry of the World Health Organization (WHO), in Geneva, Switzerland.

\section{Gabriel Behr Gomes Jardim}

Médico. Residência Médica em Psiquiatria no Hospital São Lucas, em Porto Alegre, RS, Brasil. Mestre em Gerontologia Biomédica pela Pontificia Universidade Católica do Rio Grande do Sul (PUCRS), em Porto Alegre, RS, Brasil. Médico assistente em psiquiatria geriátrica no Service Universitaire de Psychiatrie de l'Age Avancée do Centre Hospitalier Universitaire Vaudois (CHUV), em Lausanne, Suiça.

\section{Alfredo Cataldo Neto}

Médico. Doutor em Medicina e Ciências da Saúde pela Pontifícia Universidade Católica do Rio Grande do Sul (PUCRS), em Porto Alegre, RS, Brasil; professor da Pontifícia Universidade Católica do Rio Grande do Sul (PUCRS), em Porto Alegre, RS, Brasil.

\section{Endereço para correspondência}

Guilherme Nogueira

Avenida Ipiranga, 6681, prédio 81, sala 703

Jardim Botânico, 90.610-000

Porto Alegre, RS, Brasil

Os textos deste artigo foram revisados pela Poá Comunicação e submetidos para validação do(s) autor(es) antes da publicação. 